\title{
Microstructure and Mechanical Anisotropy of Ni-Mo-Cr-Based Alloy Manufactured by Laser Metal Deposition
}

\author{
Kyu-Sik Kim ${ }^{1}$, Chul-O Kim ${ }^{2}$, Soon-Hong Park ${ }^{3}$, Bandar AlMangour ${ }^{4}$ and Kee-Ahn Lee,* \\ ${ }^{1}$ Department of Materials Science and Engineering, Inha University, Incheon 22212, Korea \\ ${ }^{2}$ Vitzrotech, Ansan, 15603, Korea \\ ${ }^{3}$ Research Institute of Industrial Science \& Technology, Pohang 37673, Korea \\ ${ }^{4}$ School of Engineering and Applied Sciences, Harvard University, Cambridge, MA 02138, USA
}

This study investigated the microstructure and mechanical anisotropy of laser metal deposited Ni-Mo-Cr super alloy. The laser metal deposited Ni-Mo-Cr super alloy showed a unidirectional micro-columnar structure. The $\gamma$ phase was observed in the form of fine dendrites, and $\mathrm{M}_{6} \mathrm{C}$ (fishbone type) was shown in inter-dendrite regions. A room temperature compression test was conducted on specimens prepared in different directions (ND, PD), with strain rates of $10^{-3} \sim 1 \mathrm{~s}^{-1}$. As the strain rate increased, there was a tendency for strength to increase in both directions. As compression stress was applied, $\mathrm{M}_{6} \mathrm{C}$ fractured and aligned in the vertical direction of compression, and linear fracturing occurred in the $\mathrm{PD}$ (printing) direction, and zig-zag fracturing occurred in the ND (normal) direction. As the strain rate increased, the fractured $\mathrm{M}_{6} \mathrm{C}$ size became finer, and cracks were formed and developed along the carbides that caused the fracturing. In particular, while detachment occurred due to carbides in the ND direction, a more compressed form was observed in the PD direction. Therefore, it is considered that the PD direction has relatively higher yield strength and greater strain rate sensitivity than the ND direction. [doi:10.2320/matertrans.M2018163]

(Received May 11, 2018; Accepted August 16, 2018; Published October 1, 2018)

Keywords: laser metal deposition, Ni-Mo-Cr-based super alloy, microstructure, mechanical anisotropy, strain rate effect

\section{Introduction}

Ni-based super alloy has outstanding properties that allow it to be used for parts that are exposed to aggressive environments in the petrochemical and power plants industries. ${ }^{1,2)} \mathrm{Ni}-\mathrm{Mo}-\mathrm{Cr}$-based Hastelloy alloy was originally developed for nuclear plant parts, but its moderate mechanical properties, outstanding corrosion resistance and superior oxidation resistance allow it to be used in other industrial applications, aerospace and power plants. ${ }^{3-5)}$

The major strengthening mechanisms of Ni-Mo-Cr-based alloy are the solid solution strengthening of $\mathrm{Cr}$, Fe and carbide dispersion strengthening. ${ }^{6,7)}$ In terms of mechanical properties, however, anisotropy and strain rate response vary according to microstructural changes, particularly in texture, grain size, carbide type and distribution. ${ }^{6,7)}$ In other words, these physical properties must be ensured for use in actual parts, and the interpretation of physical properties in relation to microstructures is considered to be a critical aspect in optimizing the manufacturing process. Furthermore, Ni-Mo$\mathrm{Cr}$ alloy is in demand to be used for parts with complex shapes that maintain physical properties.

Additive manufacturing (AM) is a method that has recently been the subject of various studies, and it is used to build near-net-shape parts using 3D CAD models. ${ }^{8-10)}$ AM uses layer-by-layer depositing with powder bed deposition or direct powder deposition to build the shapes of parts. Therefore, it is receiving interest as it can minimize the loss of materials and easily manufacture complex shapes. In the case of laser metal deposition (by powder feeding), which uses a high-power laser beam to directly spray and deposit metal powder, it has the advantage of greater manufacturing speed, capability of producing relatively larger parts and

*Corresponding author, E-mail: keeahn@inha.ac.kr application to 3D-shaped base metals compared to powder bed deposition, and these advantages were utilized in attempts to manufacture bulk and coating layers with $\mathrm{Ni}$ based super alloys. ${ }^{11-16)}$ Previous studies have reported microstructural interpretation according to variables concerning the manufacturing process, ${ }^{11,15)}$ defect formation such as pores and cracks. ${ }^{11,13)}$ Most studies present the basic mechanical properties of Ni-based materials manufactured with additive manufacturing. ${ }^{12,14)}$ However, as it is common for the microstructures of laser metal deposited alloys to vary according to the direction, it is critical to implement mechanical property analysis in conjunction with microstructures. Furthermore, there is need for studies that investigate the influence of the anisotropy of microstructures and mechanical properties and strain rate.

In general, Ni-based super alloys manufactured with the laser metal deposition method achieve greater strength compared to cast materials due to solidification based on the rapid cooling of the molten pool. ${ }^{12)}$ The microstructure of the manufactured specimen is reported to form a fine dendrite structure, and therefore lead to unidirectional solidification according to the heat transfer direction. ${ }^{16)}$ As such, it is possible to estimate the anisotropy of the mechanical properties of $\mathrm{Ni}-\mathrm{Mo}-\mathrm{Cr}$ alloy manufactured by LMD according to its direction.

This study manufactured a plate with $\mathrm{Ni}-\mathrm{Mo}-\mathrm{Cr}-$ based alloy using laser metal deposition. The specimen was used to identify microstructural characteristics according to the direction in which $\mathrm{Ni}-\mathrm{Mo}-\mathrm{Cr}$ alloy was manufactured by LMD. Also, attempts were made to interpret them in relation to mechanical properties according to direction, and changes in mechanical properties according to the strain rate were reviewed in relation to the microstructural characteristics. 
(a)

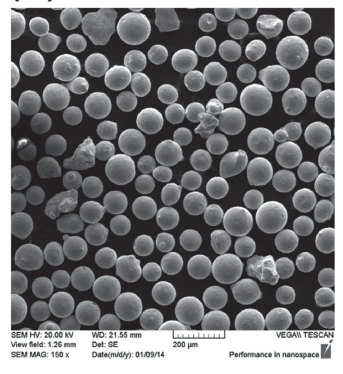

(b)

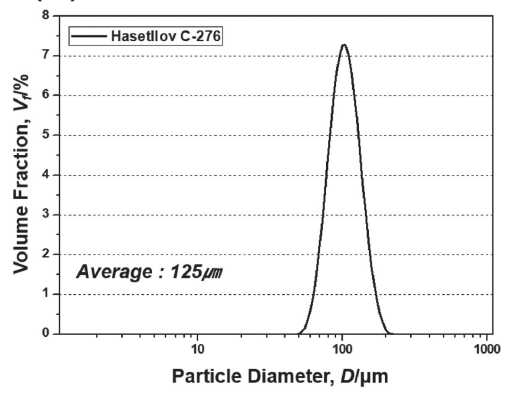

Fig. 1 Ni-Mo-Cr-based alloy powder feedstocks used in this study: (a) morphology and (b) size distribution of powder particles.

\section{Experimental Procedure}

This study manufactured a vertical direction plate with $\mathrm{Ni}-$ Mo-Cr (Hastelloy C-276) using powder feeding type laser metal deposition (LMD). The composition of the powder used in LMD was $\mathrm{Ni}-15 \mathrm{Mo}-14.5 \mathrm{Cr}-3 \mathrm{~W}-4 \mathrm{Fe}-2.5 \mathrm{Co}-$ $0.08 \mathrm{Si}-1 \mathrm{Mn}-0.01 \mathrm{C}$ (mass \%), in a spherical shape with an average grain size of $125 \mu \mathrm{m}$ (Fig. 1). Argon was used as the carrier gas, the laser power was $3.0 \mathrm{~kW}$ with a scan speed of $8 \mathrm{~mm} / \mathrm{s}$, and SUS 304 plate was used as a substrate. The substrate was laminated repeatedly in one direction at barometric atmosphere to manufacture a plate specimen with dimensions of $67.5(\mathrm{~W}) \times 3(\mathrm{~T}) \times 19(\mathrm{H}) \mathrm{mm}^{3}$.

To perform phase analysis of the $\mathrm{Ni}-\mathrm{Mo}-\mathrm{Cr}$ alloy manufactured by LMD, an X-ray diffractometer (XRD, Rigaku, Rapid-S) was used. The specimen underwent grinding up to \#2000 SiC paper, and micro polishing was performed using $1 \mu \mathrm{m}$ diamond suspension. Then, the specimen underwent electrolytic etching using $85 \mathrm{ml}$ $\mathrm{H}_{2} \mathrm{O}+10 \mathrm{ml} \mathrm{H}_{2} \mathrm{NO}_{3}+5 \mathrm{ml} \mathrm{CH}_{3} \mathrm{COOH}$ solution at $1.5 \mathrm{~V}$ for 10 seconds. Scanning electron microscopy (SEM, TESCAN, VEGA II LMU) and electron probe microscopy (EPMA, Shimadzu, EPMA-1600) were used to observe the microstructure and element distributions.

For the compression test, the specimen underwent further processing to produce $2 \mathrm{~mm}$ (D) $\times 4 \mathrm{~mm}$ (H) cylindrical shape compression specimens in the PD and ND directions. The compression test was performed using Gleeble equipment at room temperature, and initial strain rates of $10^{-3} \mathrm{~s}^{-1}$, $10^{-2} \mathrm{~s}^{-1}, 10^{-1} \mathrm{~s}^{-1}$ and $1 \mathrm{~s}^{-1}$ and strain limit of 0.6 were applied. To observe the microstructures before and after the compression test and to analyze the deformation behavior, scanning electron microscope (SEM, TESCAN, VEGA II LMU) and field-emission scanning electron microscope (FESEM, TESCAN, MYRA 3 XMH) were used.

\section{Results and Discussion}

Pore fraction measurement using image analysis measured $0.23 \%$ (ND), $0.33 \%$ (TD) and $0.22 \%$ (PD), indicating small differences among directions. The average pore fraction of the $\mathrm{Ni}-\mathrm{Mo}-\mathrm{Cr}$ alloy manufactured by LMD was approximately $0.26 \%$, which indicates that the material can be manufactured very densely. However, as shown in Fig. 2, fine spherical pores (white arrows) were observed in the $\mathrm{Ni}-\mathrm{Mo}-\mathrm{Cr}$ alloy manufactured by laser metal deposition. The fine spherical pores, which were mainly found in the ND direction, had a unique shape. In material manufactured using conventional casting processes, spherical gas pores form due to gas traps and shrinkage pores aligned in random directions form due to cooling shrinkage. ${ }^{13)}$ This seems to be caused by the characteristics of manufacturing. As for laser metal deposition, lamination and solidification occur in a sequence, and to ensure this, heat transfer mainly takes place in the matrix or pre-deposited direction. The spherical pores seem to be formed by the Ar gas used during powder feeding being trapped.

As described above, the formation and shape of pores are related to the microstructure of the specimen manufactured by LMD, and observations of the microstructure according to directions are presented in Fig. 3. As shown in the figure, the TD and PD directions formed a columnar structured dendrite shape, while the PD direction formed lattice type (equiaxial) dendrites. In addition, dark phases were found in the interdendritic region regardless of direction. However, it is suspected that the heat transfer direction shifted according to the laser scanning strategy, scanning rate etc., and this resulted in columnar dendrites with a slope rather than a vertical direction, as observed in the microstructure. Figure 4 shows the XRD phase analysis results of the Ni-Mo-Cr alloy manufactured by LMD. Ni-Mo-Cr alloy consists of $\gamma-\mathrm{Ni}$ (solid solution; $\mathrm{Cr}, \mathrm{Fe}$ ) phase and $\mathrm{M}_{6} \mathrm{C}$ phase, and despite the fact that manufacturing was performed in a barometric atmosphere condition, XRD results did not find any oxide formation. This seems to be due to Ar, an inert gas used
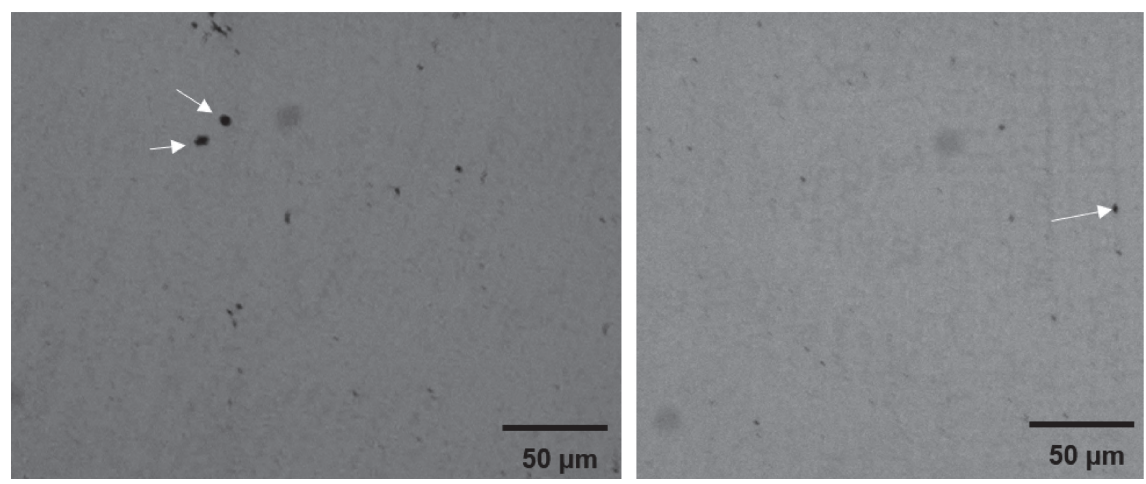

Fig. 2 Results of defect characterization of LMDed Ni-Mo-Cr alloy. 
during powder feeding, limiting the atmosphere from coming in contact with the specimen.

The $\gamma$-Ni phase identified in XRD featured different plane intensities according to manufacturing direction (Fig. 5). In the TD direction, the $(220)_{\gamma}$ plane had the highest intensity, and in the PD direction, the (220) $\gamma$ plane and $(311)_{\gamma}$ plane measured higher. On the other hand, in the ND direction, the $(111)_{\gamma}$ plane was the highest and $(220)_{\gamma}$ plane was found to some degree. As mentioned earlier concerning the microstructure, this seems to be due to directional solidification.
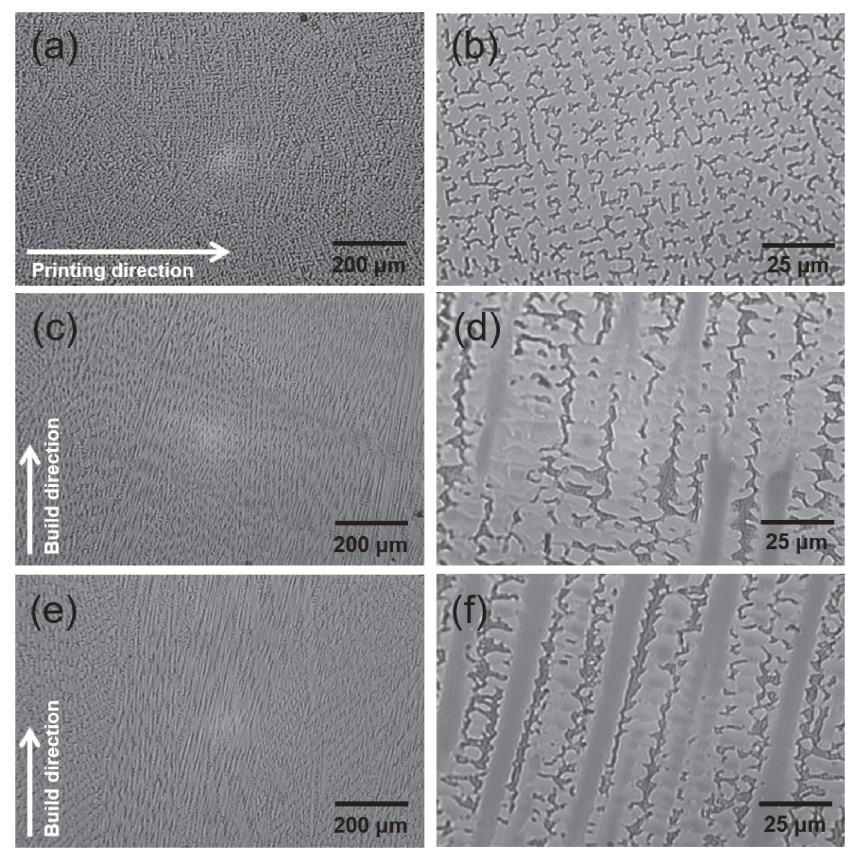

Fig. 3 Directional microstructure analysis (optical microscope): (a, b) ND, (c, d) TD, (e, f) PD.
SEM was used to perform high-magnification observation of the distribution and shape of the dark phases identified in Fig. 3, and Fig. 6 presents the observation results. While a unique fishbone shape was observed regardless of direction, the distribution varied according to direction, as shown in the figure. The above-mentioned phase formed an alignment in the building direction in the TD and PD directions. Figure 7 is the EPMA phase analysis of the fishbone phase in the microstructure to identify its elemental distribution. The fine dendrites were confirmed to be $\gamma$-Ni (solid solution; $\mathrm{Cr}, \mathrm{Fe}$ ), and the phase of the fishbone type phase consisted of a mixture of $\mathrm{Mo}, \mathrm{Si}$ and $\mathrm{C}$. In relation to the XRD results, it is possible to deduce that it is $\mathrm{M}_{6} \mathrm{C}(\mathrm{M}: \mathrm{Mo}, \mathrm{Si})$. V. Vitry et al. reported that fishbone type $\mathrm{M}_{6} \mathrm{C}$ is only formed by rapid cooling, and in the case of casting, it can only form on the surface or regions near the surface. ${ }^{16,17)}$ In addition, alloy elements such as $\mathrm{Mo}, \mathrm{W}$ and $\mathrm{Si}$ are reported to cause segregation in the inter-dendritic region. ${ }^{14)}$ In other words, in

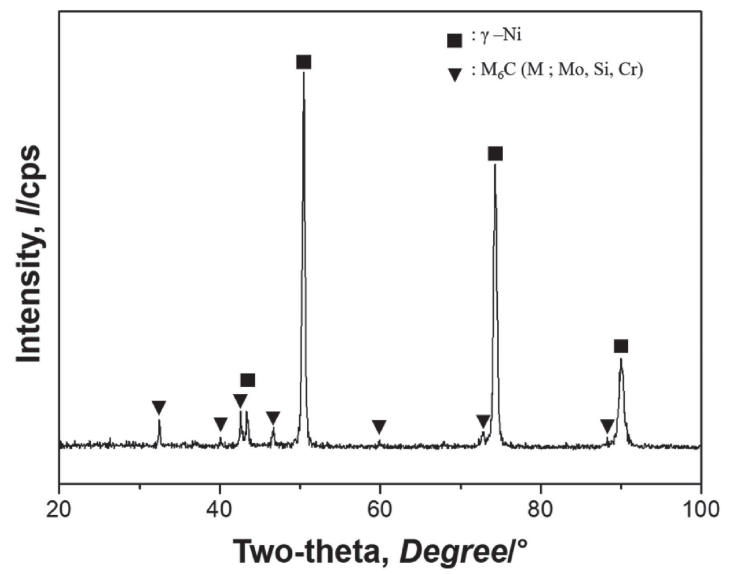

Fig. 4 XRD phase analysis results of laser metal deposited Ni-Mo-Crbased super alloy.

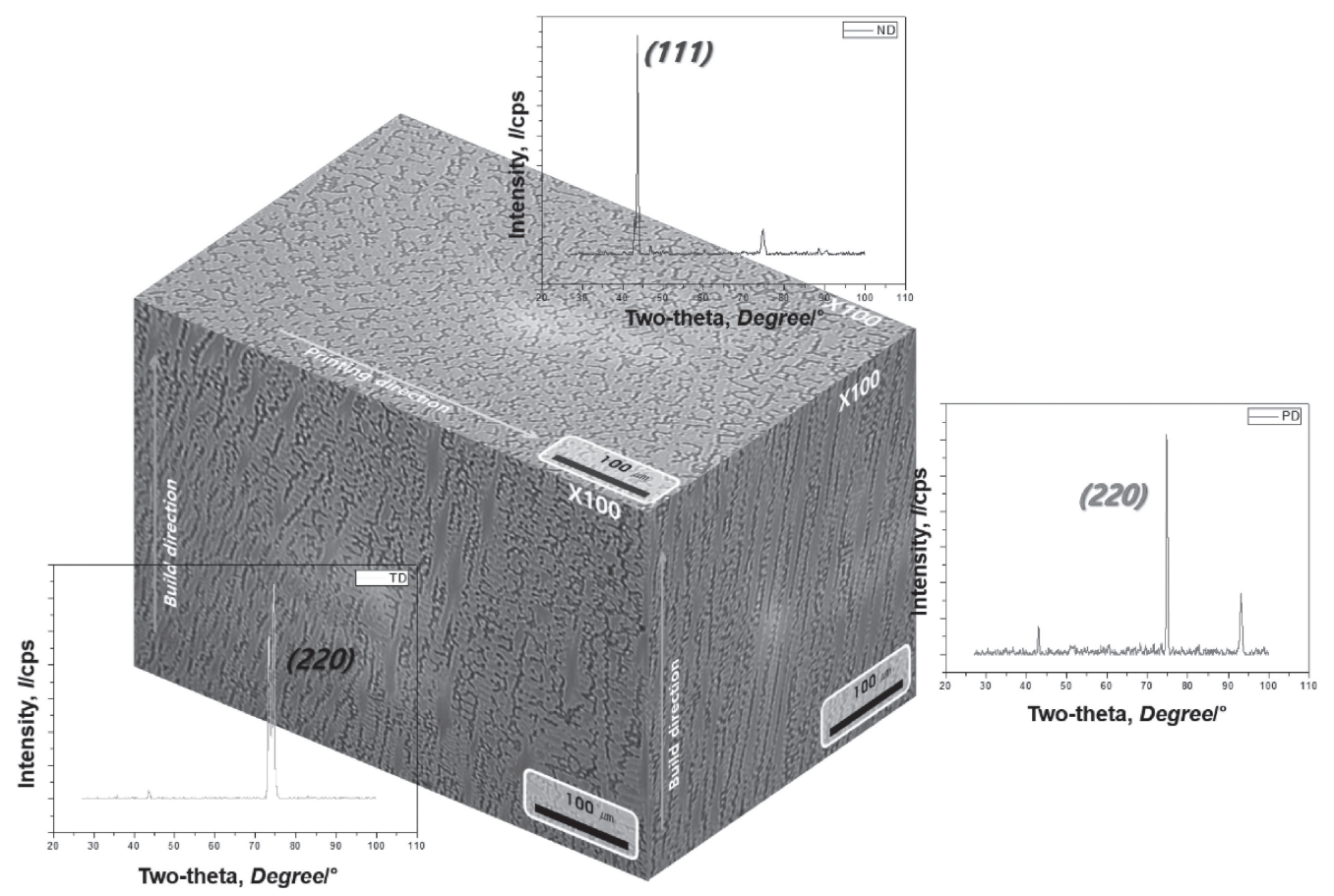

Fig. 5 Three-dimensional observation and micro-XRD analysis results of thin wall material. 

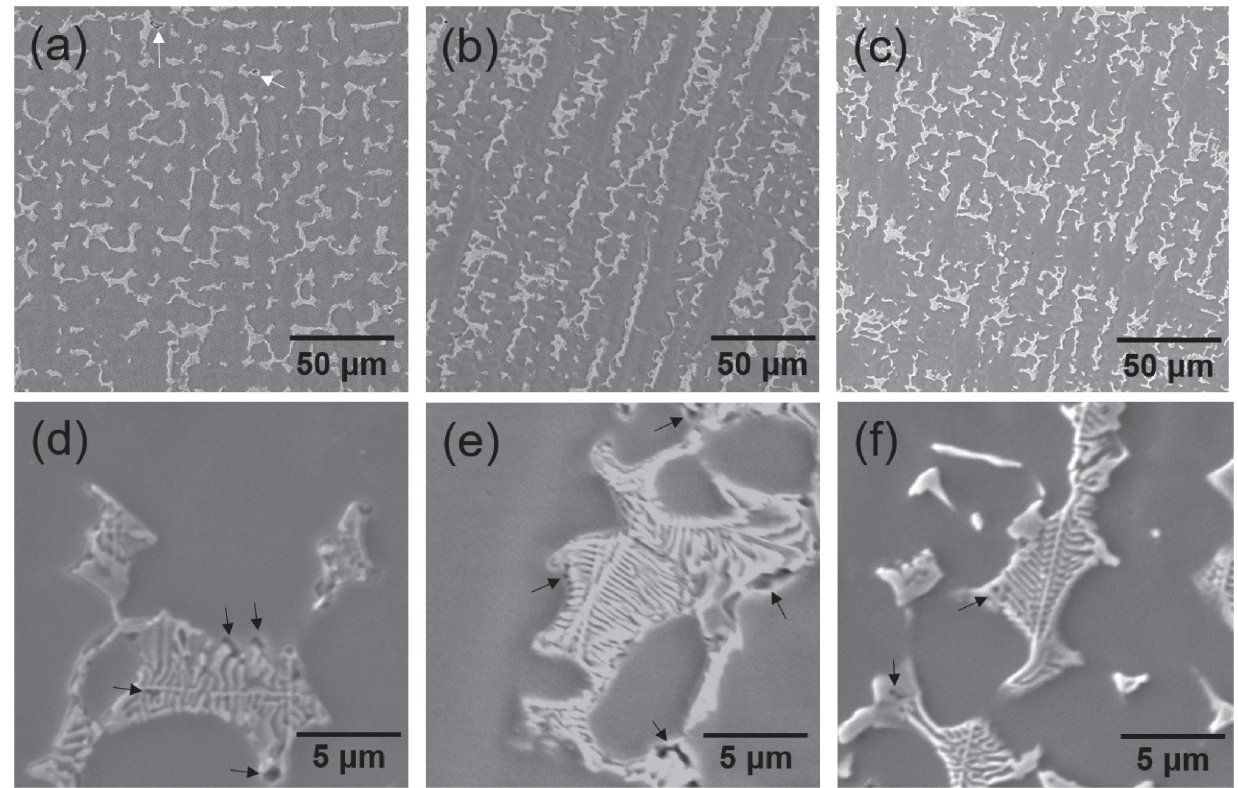

Fig. 6 Directional microstructure analysis of the specimens and EDS analysis (SEM): (a, d) ND, (b, e) TD, (c, f): PD.
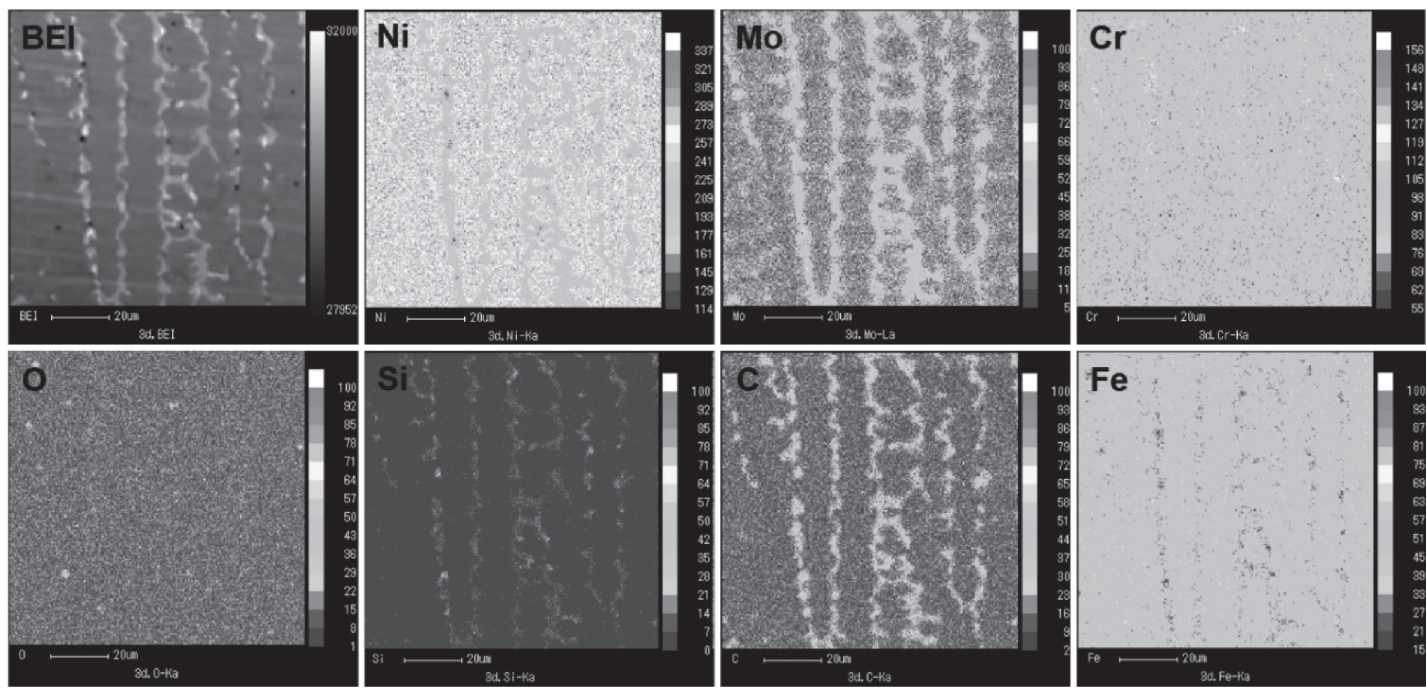

Fig. 7 Results of EPMA element distributions in laser metal deposited $\mathrm{Ni}-\mathrm{Mo}-\mathrm{Cr}$ alloy.

laser metal deposition, when the molten powder is repeatedly deposited to form a layer, and undergoes rapid cooling. Here, segregating elements such as $\mathrm{Mo}, \mathrm{Si}$ and $\mathrm{W}$ combine with $\mathrm{C}$ to possibly form fishbone type $\mathrm{M}_{6} \mathrm{C}$ in the inter-dendritic region, as V. Vitry reported, and it is possible to consider that the carbide distribution is related to the dendrite shape.

Figure 8 shows the direction of the $\mathrm{Ni}-\mathrm{Mo}-\mathrm{Cr}$ alloy manufactured by laser metal deposition and compressive deformation behavior according to the strain rate. When compressed at a strain rate of $10^{-3} \mathrm{~s}^{-1}$, the Ni-Mo-Cr alloy manufactured by laser metal deposition achieved compressive yield strength of $486.9 \mathrm{MPa}$ (ND) and 504.4 MPa (PD), and such are greater than the approximately $350 \mathrm{MPa}$ of common Hastelloy C-276 manufactured by casting. ${ }^{1)}$ As the strain rate increased, the ND direction yield strength increased to 554.6 MPa, 584.2 $\mathrm{MPa}$ and $615.7 \mathrm{MPa}$, and the PD direction yield strength also indicated a general tendency to increase: to $507.4 \mathrm{MPa}$; $592.8 \mathrm{MPa}$; and $635.2 \mathrm{MPa}$. In the case of yield strength, no significant difference was found according to the direction, but the yield strength in the PD direction achieved a slightly greater value, which seems to be due to the microstructural differences caused by unidirectional solidification, as described above. Measurement of strain rate sensitivity of a strain rate according to the specimen's direction using yield strength recorded 0.032 in the ND direction and 0.036 in the PD direction. Thus, strain rate sensitivity also did not show a significant difference, but the PD direction showed slightly higher strain rate sensitivity.

Figure 9 shows the observation results of the deformed structure of the compression specimen according to strain rate in the ND and PD directions. After the compression test, the fishbone type $\mathrm{M}_{6} \mathrm{C}$ was fractured to fine carbides. The shape and distribution of the fractured carbide varied according to direction. In the case of ND direction (b), the $\mathrm{M}_{6} \mathrm{C}$ changed into a zig-zag form as compression was applied. In the case of PD direction (a), it was stretched in 
(a)

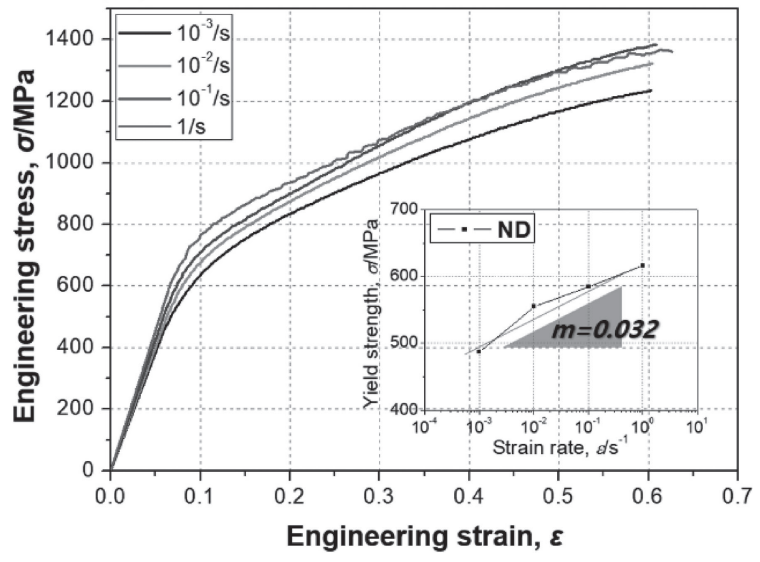

(b)

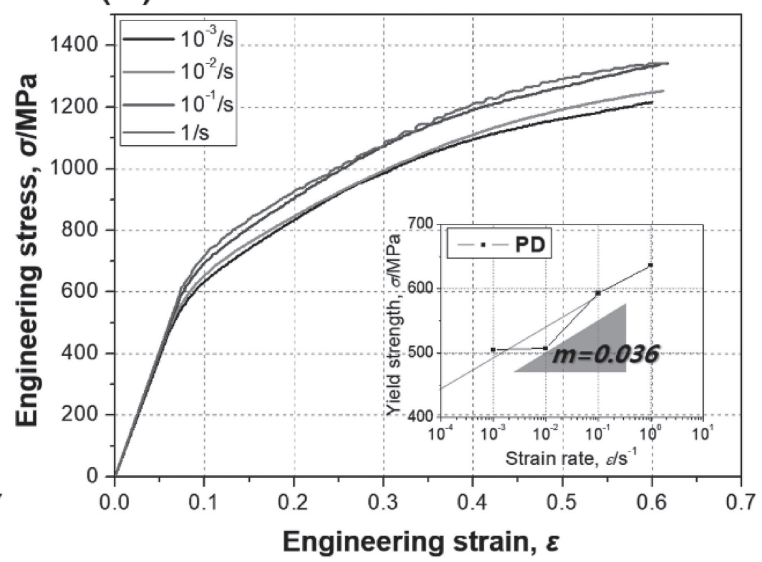

Fig. 8 Compressive results according to the strain rate $\left(10^{-3} / \mathrm{s}, 10^{-2} / \mathrm{s}, 10^{-1} / \mathrm{s}, 1 / \mathrm{s}\right)$ : (a) ND, (b) PD.

(a)

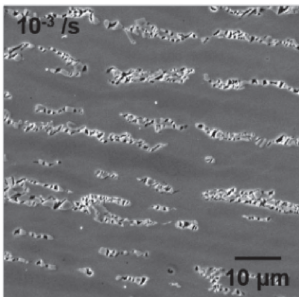

(b)

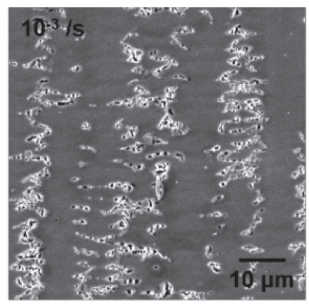

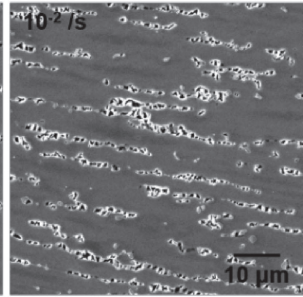

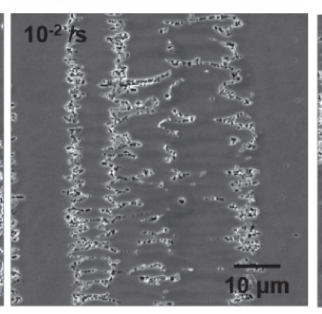

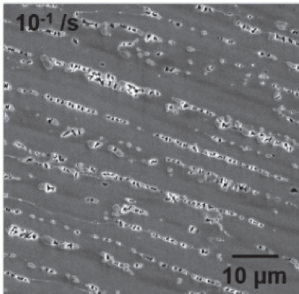

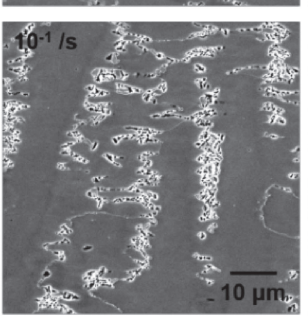

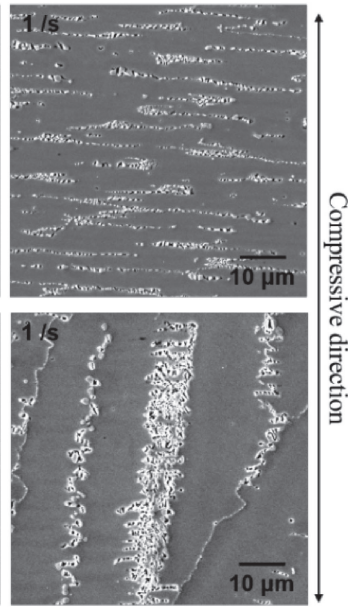

Fig. 9 Results of microstructure analysis after compressive test according to the strain rate $\left(10^{-3} / \mathrm{s}, 10^{-2} / \mathrm{s}, 10^{-1} / \mathrm{s}, 1 / \mathrm{s}\right)$ : (a) PD, (b) ND.

a linear form, unlike the zig-zag form found in the ND direction. Also, fractured $\mathrm{M}_{6} \mathrm{C}$ was distributed in a similar form regardless of strain rate, but as the strain rate increased, it was observed that the size of the fractured carbide became finer.

Figure 10 is a representation of the internal crack propagation behavior in the compression specimen as a schematic diagram. In the PD direction, crack propagation in the horizontal direction along carbides was also found in the fracture surface of compressed samples. The fishbone type $\mathrm{M}_{6} \mathrm{C}$, failed to maintain its shape and was deformed after compression, and then was realigned in the horizontal direction, resulting in the propagation of internal cracks along the direction. As such, it seems that fractured $\mathrm{M}_{6} \mathrm{C}$ caused cracks within the compression specimen while being a propagation path. On the other hand, vertical cracks were observed in the ND direction, and fracture surface observation discovered columnar dendrites vertically aligned in the interior. Carbide alignment took the same direction as the compression direction, thus resulting in cracks forming along carbides in the direction.

Based on the above findings, it is possible to explicate the anisotropy of the mechanical properties of $\mathrm{Ni}-\mathrm{Mo}-\mathrm{Cr}$ alloy manufactured by laser metal deposition. (220) $\gamma$-Ni plane alignment was most commonly observed in the PD direction and (111) $\gamma$-Ni plane alignment was observed in the ND direction, which suggests that the slip system activated due to compression could be different. However, $\gamma$-Ni features various slip systems in a grid form of the FCC structure, making it a phase susceptible to plastic deformation, and it is expected to make no major contributions to the overall strength. On the other hand, $\mathrm{M}_{6} \mathrm{C}$ carbide contributes as a brittle strengthening phase, and it also acts as a crack propagation path. In the case of the ND direction, as cracks propagate in the compression direction (carbide alignment direction), tension occurs between cracks, causing fracturing within the specimen. On the other hand, in the case of the PD direction, the above-mentioned phenomenon occurs less, resulting in relatively higher strength and high strain rate sensitivity.

\section{Conclusion}

This study manufactured Ni-Mo-Cr alloy using laser metal deposition and analyzed the specimen's microstructure. Compressive deformation behavior was analyzed according to direction and strain rate, and the following conclusions were obtained: 
(a)

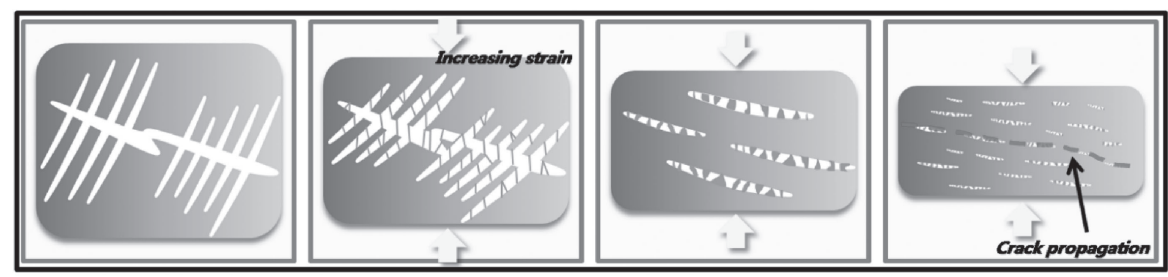

(b)

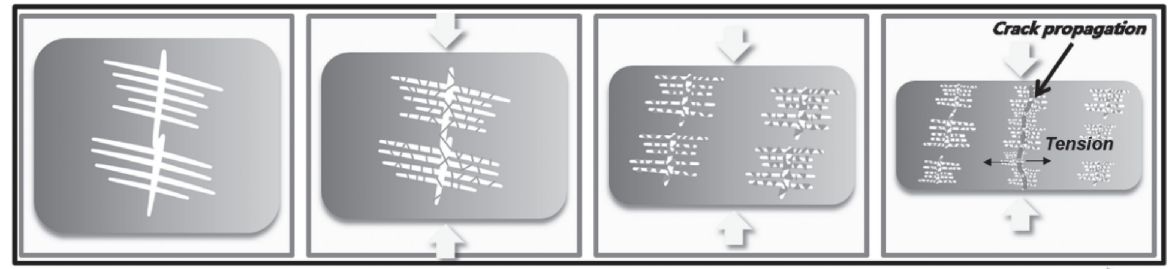

(c)

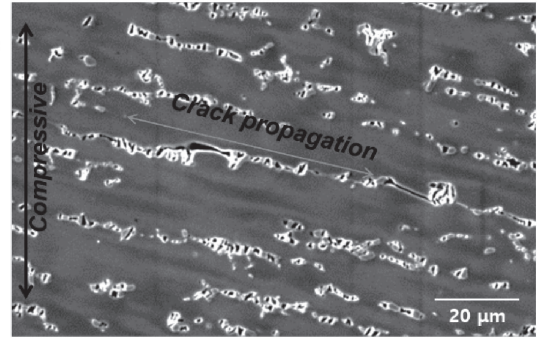

(d)
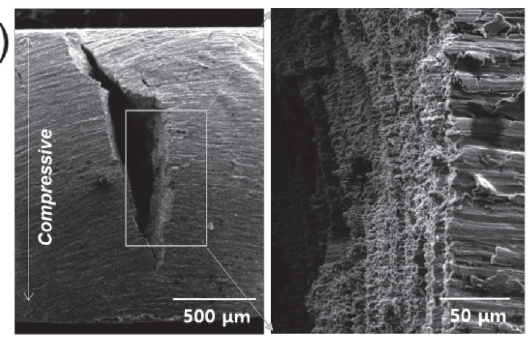

Fig. 10 Schematic diagrams of deformed microstructure according to increasing strain: (a) PD, (b) ND, and SEM observation results showing differences in crack propagation behavior with (c) PD, (d) ND.

(1) A dense Ni-Mo-Cr alloy specimen with an average pore fraction of approximately $0.26 \%$ was manufactured with laser metal deposition. It seems that directional solidification formed due to the repeated lamination of molten powder, and microstructural anisotropy was observed as a result. In the $\mathrm{PD}$ and TD directions, fishbone type $\mathrm{M}_{6} \mathrm{C}$ phase was aligned vertically to the columnar structured dendrites $(\gamma-\mathrm{Ni})$ aligned in the (220) plane. In the ND direction, on the other hand, lattice (equiaxial) dendrites aligned in the (111) plane were observed, and fishbone type $\mathrm{M}_{6} \mathrm{C}$ carbides were observed in a lattice form in the interdendrite region.

(2) A compression test according to direction and strain rate measured yield strength of $486.9 \mathrm{MPa}$ (ND) and $504.4 \mathrm{MPa}$ (PD), which are slightly higher than conventional Ni-Mo-Cr alloy manufactured by casting. Yield strength increased in both directions as the strain rate increased, and yield strength in the PD direction was slightly higher than that of the ND direction. Strain rate sensitivity $(\mathrm{m})$ in the ND and PD directions measured 0.032 and 0.036 , respectively.

(3) As compressive deformation was applied, $\mathrm{M}_{6} \mathrm{C}$ failed to maintain its original fishbone type form at all strain rates regardless of ND or PD direction, and fracturing occurred. Carbide seems to be the main cause of a slightly higher strength and strain rate sensitivity in the PD direction as it acted as a strengthening phase as well as crack path.

\section{REFERENCES}

1) J.R. Davis: Nickel, Cobalt, and Their Alloys, (ASM specialty Handbook, ASM International, Materials Park, 2000).

2) W.F. Smith: Structure and properties of engineering alloys, 2nd ed., (McGraw-Hill, New York, 1981) pp. 495-524.

3) M. Hashim, K.E. Ssrath Raghavendra Babu, M. Duraiselvam and H. Natu: Mater. Des. 46 (2013) 546-551.

4) J. Lu, E.S. Choi and H.D. Zhou: J. Appl. Phys. 103 (2008) 064908.

5) Q. Zhang, R. Tang, K. Yin, X. Luo and L. Zhang: Corros. Sci. 51 (2009) 2092-2097.

6) K.K. Mehta, P. Mukhopadhyyay, R.K. Mandal and A.K. Singh: Metall. Mater. Trans. A 45 (2014) 3493-3504.

7) N.R. Jaladurgam and A.K. Kanjarla: Mater. Sci. Eng. A 712 (2018) 240-254.

8) X. Wu and J. Mei: J. Mater. Process. Technol. 135 (2003) 266-270.

9) F. Wang: Int. J. Adv. Manuf. Technol. 58 (2012) 545-551.

10) L.E. Murr, E. Martinez, K.N. Amato, S.M. Gaytan, J. Hernandez, D.A. Ramirez, P.W. Shindo, F. Medina and R.B. Wicker: J. Mater. Res. Technol. 1 (2012) 42-54.

11) M. Cloots, P.J. Uggowitzer and K. Wegener: Mater. Des. 89 (2016) 770-784.

12) Y. Li, H. Qi, H. Hou and L. Lei: Adv. Eng. Res. 102 (2017) 31-40.

13) J. Li, S.L. Shrestha, Y. Long, L. Zhijun and Z. Xintai: Mater. Des. 93 (2016) 324-333.

14) Y. He, J. Yang, W. Fu, L. Wang and Z. Gao: J. Alloys Compd. 673 (2016) 8-16.

15) N. Perevoshchikova, J. Rigaud, Y. Sha, M. Heilmaier, B. Finnin, E. Labelle and X. Wu: Rapid Prototyping J. 23 (2017) 881-892.

16) S.-H. Sun, K. Hagihara and T. Nakano: Mater. Des. 140 (2018) 307316.

17) V. Vitry, S. Nardone, J.-P. Breyer, M. Sinnaeve and F. Delaunois: Mater. Des. 34 (2012) 372-378. 